\title{
Chest Compressions in "Patients who Have Undergone Cardiac Surgery"
}

Seiji Morita ${ }^{1}$, Mari Amino ${ }^{2}$, Hiromichi Aoki ${ }^{1}$ and Sadaki Inokuchi ${ }^{1}$

Key words: chest compression, cardiac surgery

(Intern Med 53: 635-636, 2014)

(DOI: 10.2169/internalmedicine.53.1903)

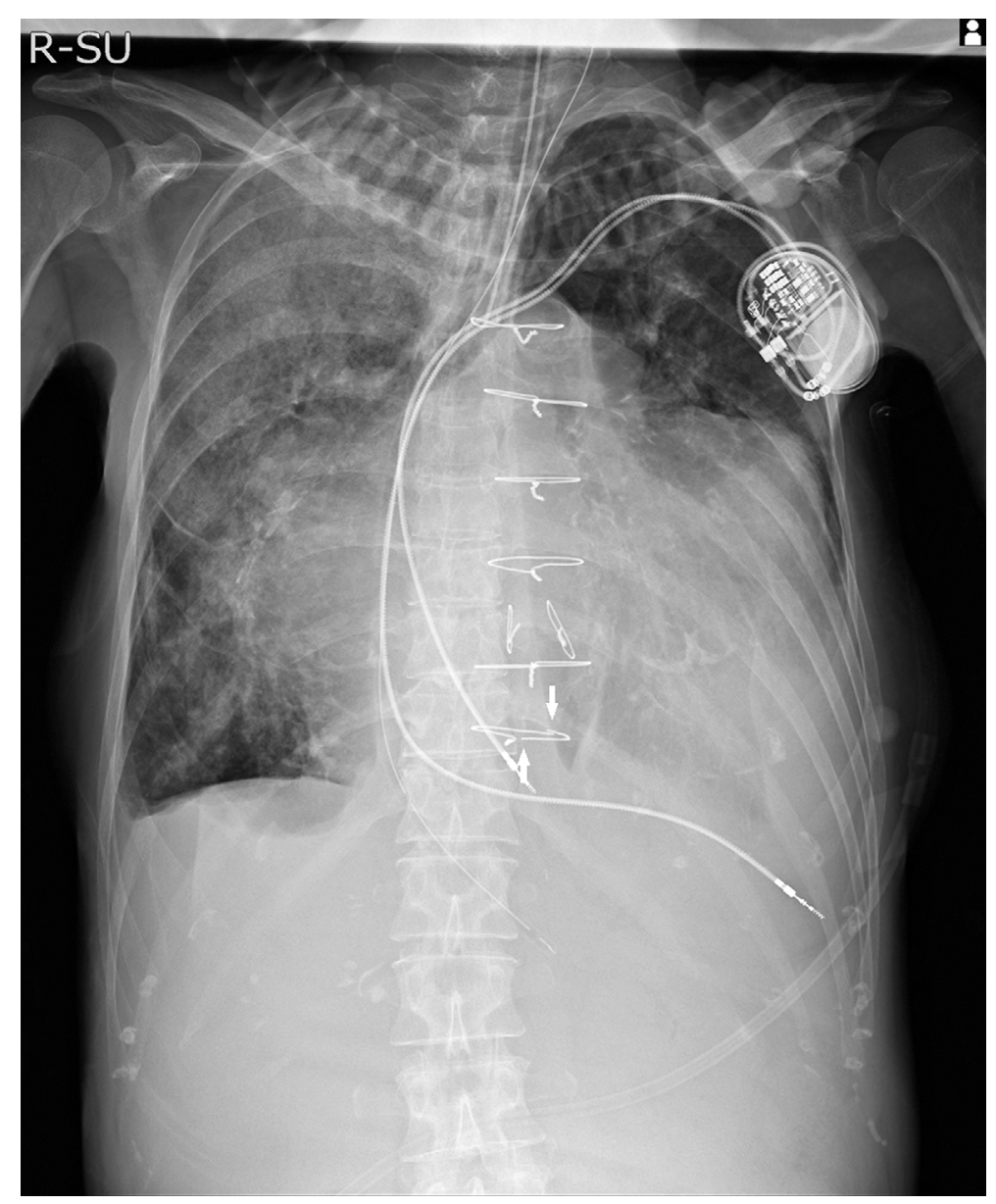

Picture.

Chest compression (CC) constitutes the most popular and effective cardiopulmonary resuscitation technique employed by civilians and medical staff. This report documents the risk of harm during CC. A 72-year-old woman called for an ambulance due to dyspnea. She experienced cardiopulmo- nary arrest upon arrival of the ambulance and was administered CC. After two cycles of $\mathrm{CC}$, the paramedic experienced pain and realized that his right palm was injured. The patient had undergone cardiac surgery 20 years previously, and a part of the wire had escaped through the surgical scar

${ }^{1}$ Department of Emergency and Critical Care Medicine, Tokai University School of Medicine, Japan and ${ }^{2}$ Department of Cardiovascular Medicine, Tokai University School of Medicine, Japan

Received for publication October 12, 2013; Accepted for publication October 15, 2013

Correspondence to Dr. Seiji Morita, morita@is.icc.u-tokai.ac.jp 
from the median sternotomy. An initial chest roentgenogram indicated damage to the wire (Picture).

Bystander civilians and medical staff who provide $\mathrm{CC}$ to patients who have undergone surgery using the median sternotomy approach are at risk of injury and infection. Considering that the application of immediate and continuous CC is the recommended emergency treatment, information regarding the risks of this procedure and the prevention of such risks must be provided to civilians and medical staff.

The authors state that they have no Conflict of Interest (COI).

(C) 2014 The Japanese Society of Internal Medicine http://www.naika.or.jp/imonline/index.html 